\title{
On Bilingual Teaching Design in Management Curriculum Based on CBI
}

\author{
Huiyan. Li
}

Management Department, Sanya University, Hainan, P.R.China, 572000

\author{
Hao.Wang \\ Sanya Aviation \& Tourism College, School of Tourism \& Hotel Management, Hainan, P.R.China, 572000
}

\begin{abstract}
Appropriate courses teaching is the key to successful teaching and learning. In the practice of bilingual curriculum in China's universities nowadays, the teacher can apply the idea of CBI to designing bilingual courses. CBI is an instructional theory that entails a combination of course content and language teaching as well as that of academic skill learning and L2 acquisition. By practicing designing courses, the teacher may become more capable of promoting the instruction of bilingual teaching in our universities management type curriculum.
\end{abstract}

KEYWORD: CBI; Bilingual teaching; Curriculum

\section{INTRODUCTION}

According to "Longman Dictionary of Applied Linguistics" is defined, bilingual education refers to the use of a second language or foreign language teaching a variety of subjects in school. According to the relevant provisions of "University Undergraduate Teaching Evaluation Program (Trial)" of the Ministry of Education, "bilingual education" course refers to the "use of foreign language textbook and teaching hours to reach $50 \%$ over the course hours (except foreign language class)." Bilingual education can be divided into three types, including: immersion bilingual education refers to a language the school using in teaching instead of the students using at home; keeping bilingual education refers to the use of the mother tongue student just entering school, and then gradually use a second language for teaching some subjects, the use of mother tongue teaching other subjects still; transitional bilingual education refers to some or all of the students use mother tongue after entering the school and then gradually transformed into using a second language for teaching only.[1] In bilingual education, the main purpose is the acquisition of professional knowledge, but also to create learner space to learn and use second language, so that students acquire subject knowledge and at the same time can use a second language as much as possible they need to master. The ultimate aim is to enable students think problem using both native and second language, to switch between the two languages as communication objects and work environment required, have the ability to cross-cultural communication and establish cross-cultural awareness.

With the accelerating pace of economic globalization and the deepening of China's opening up, economic and social demand for both proficient in foreign languages and obtain comprehensive knowledge of high-quality, complex, applicationoriented talents is growing. In 2001, The Department of Higher Education required "actively pursuing bilingual teaching in undergraduate education using English and other foreign languages" and launched bilingual education teaching demonstration curriculum construction projects in 2007, especially in professional of IT, biological sciences, management, finance, law, etc. should strive to make foreign language taught courses reach $5 \%$ to $10 \%$ of the open curriculum within 4 years. There has built 502 bilingual teaching demonstration programs in 2011. However, due to the training goals are different in universities, professional courses categories complicated, academic backgrounds of teachers various and other reasons, the development and design bilingual teaching course can not be unified at the national or regional level like the stage of basic education curriculum. Thus, bilingual teaching course in different universities or professional bilingual courses in the same university has shown a school-based orientation and individualized features. We can say that the practice of bilingual teaching course has a unified national policy and school level guidance, but it is more personalized curriculum design which the classroom teachers perform under the guidance of curriculum 
objectives and according to the curriculum and teaching philosophy, professional level and direction of research, as well as students' ability. Thus, the ability of teachers to design and develop curriculum directly related to the success of bilingual programs. This prompted us to give enough attention to develop and design capabilities of university teachers for dealing with bilingual courses.

\section{OVERVIEW OF CBI CONCEPTS}

CBI (content-based language instruction) teaching, also known as "content-based language teaching," or "integrated language instruction", and the literature often referred to CBI, it is foreign language teaching method rise since the mid 1980s in West, also a new concept the second language and foreign language courses design. There have a variety of definitions Scholars from different angles. Brinton think that CBI was "kind of teaching which combine a specific subject content with language teaching objectives and the teaching in current academic fields with the second language skill"; Crandall \& Tucker believes that "CBI is a language teaching method that combines the topics and tasks selected from the subject content, such as mathematics and social studies." CBI teaching objectives is to develop a second language or foreign language skills and obtain outstanding ability to use content and language in the process of learning specific subject content. In academia, CBI received support from the second language research, education psychology, teaching strategies and other research areas. From the education practical, CBI also gained some experience and effectiveness, "When foreign or second language linked with academic content, we get more effective learning outcomes than learning a second language isolated."[2]

Therefore, considering the course design, CBI teaching refers to a curriculum design concept which teachers decides the teaching material to use, the learning tasks, the classroom teaching strategies and assessment tools with academic content areas as the teaching objectives in a second language, foreign language and bilingual teaching. In this curriculum design guide, a second or foreign language is not learning object, but as a tool in natural science and social science academic content teaching. In this process, students not only to master the content of disciplines, but also learned a second language or foreign language.

The research put forward the idea of bilingual curriculum design for the college management courses performed by teachers with CBI teaching philosophy rise in a second foreign language and foreign language teaching area, hoping to promote the innovative reform of foreign language teaching in non-English professionals of domestic universities, and promote the awareness and ability of various types of non-English professional teachers in university as a "course designers", and to promote their professional development of teachers, so that teachers become conscious curriculum designers gradually.

\section{OUR UNIVERSITY MANAGEMENT CLASS BILINGUAL TEACHING DESIGN GUIDED BY CBI}

Clear educational philosophy is an important prerequisite for curriculum design. Rigorous teaching objectives and effective use of language learning materials as well as emphasis on using certain forms of language is the foundation of learning success under CBI background. Thus, after clearing CBI theory as a bilingual curriculum design basis, the teachers should take a full range of designs from the teaching objectives, course contents, teaching strategies and assessment methods on the basis of the investigation of student learning needs.

\subsection{Balancing the dual goals and construct the threefold goal}

Course objectives are expected outputs or outcomes of a course, establishing goals play an important role in guiding teachers to teach and students to learn. Under the guidance of CBI teaching philosophy, bilingual curriculum goals should seek to achieve a balance in terms of language and content objectives in order to complete the dual commitment of language and content learning. Note the following:

Firstly, clear the center of gravity of course objectives. Dual goals do not mean that teachers must achieve absolute balance in both content and language, but reasonably determine the dual goals according to the nature and tasks of the bilingual curriculum, as well as the needs of students. Some courses focus on language and some on content. During the course design, Mimi Met frame can provide a reference, that is, on a bipolar contentdriven and language-driven project coordinates find the position of the bilingual curriculum. For example, the main teaching purpose of immersion is the subject content, which is in the extreme right end. The language classes with frequent use of content for practice are obviously language-oriented and lie in the extreme left end in the coordinates. From the perspective of curriculum design, the nature of our current university professional bilingual curriculum should be in the right part of the coordinates in general, that the goal is to grasp and understand the subject with academic language as the carrier.

Secondly, build the threefold goal. Just noticed balance the dual goals still is not enough. Stoller 
think through the second language should be able to bring more in-depth study of the subject matter, his harvest is even threefold. It can help students build knowledge and understanding of a topic or field, to learn and use the language in a meaningful and purposeful strong environment.[3] In fact, the use of authentic language can help students get the most primitive forms of discourse, in the most direct way to get to know the principles of discipline, to avoid loss and distortion of the information caused by misinterpretation and language conversion, reaching for a deeper understanding of course content.

\subsection{Integrated curriculum language and subject matter to reflect the internal consistency}

Bilingual curriculum and teaching often encountered difficulties in the textbook selection. The difficulty of language, the depth and breadth of content will often beyond understanding and acceptance of foreign language learners if teachers use original materials. If teachers themselves selected appropriate content as a textbook, they will need to have higher language skills and master certain writing theory. However, this is the only way for our bilingual curriculum development and teacher professional development.

Firstly, simplify the disciplines content and structure appropriately. Compared with native language professional courses, bilingual curriculum will usually be questioned whether affecting students understand and master the content because of language problem. For example, whether the entire disciplinary system is complete or not and whether the specific content of each unit has enough depth and enough capacity? We need to revisit the balance of dual goals and the construction of the threefold goal of bilingual programs to answer these questions. We must recognize that the bilingual curriculum is the third type courses different from the original curriculum. It does not necessarily have to achieve the same goal as the native language courses, we can not require its teaching content exactly the same in thought depth and capacity as the native language courses. In most cases, the preparation of a bilingual curriculum materials must be appropriate to simplify in the subject content and structure, and at the same time use rich media in teaching, such as image data recorded in second or foreign language, PPT prepared by the second or foreign language, as well as extracurricular reading material, etc. to integrate second language and foreign language successful into teaching. As for the depth of content and ideological content requirements, rely necessary on teaching strategies to supplement.

Secondly, reduce the difficulty of foreign or second language appropriately. For learners of bilingual curriculum, the second or foreign language is not only a tool for them to learn academic knowledge, but is part of the learning objectives. As a language tool, if the difficulty have beyond the students foundation, the teachers and students have to spend a lot of time to solve the language problem, making the learning center of gravity tilt, professional courses evolved into intensive language courses, goals confusion, then affecting student confidence and enthusiasm for learning subject content. Therefore, it bound to adapt to the students' ability in the language difficulty.

Thirdly, establish the consistency of internal content. Simplify the content and structure is likely to cause the front and rear of textbook not linked, so that students can not get holistic cognitive of disciplines. This fracture, broken knowledge will cause great difficulties on student learning. Stroller proposed the three methods to make curriculum content linked and obtain the internal consistency. Scrutinize is to confirm that topics organized by theme-centered; Design planned transitions among various tasks and topics; Pay attention to connect specific content of each part with threads.

\subsection{Rich teaching strategies and organize comprehensible input and meaningful output}

With appropriate teaching materials, teachers also need to adopt appropriate teaching strategies in the classroom to guide effective teaching. But regardless of bilingual education teachers or students have a considerable challenge. Teachers in the classroom teaching strategies and means single, the majority of students did not accustom to the language as a medium to acquire knowledge, often effort a lot in the foreign words and language form but ignored the thinking of subject problems pointed by the language. These issues require teachers to adopt appropriate teaching strategies to resolve.

Teachers must diversify teaching methods to help students understand and master the subject content. Teaching must "intelligibility" in language and content.[4] First, we must make full use of the students' prior knowledge to enable students to clear the significance of bilingual curriculum is to bring us a different perspective to understand the theoretical disciplines and can also get the acquisition of professional disciplines language and thought, thus establish the correct psychological expectations. Second, the different topics and target should input differently. Teachers can use the lecture method by using the second or foreign language. Be sure to make yourself teach in one language, rather than allowing students to rely on foreign exchange of "translate" teaching. Teachers can also use some auxiliary teaching strategies, such as arrangements for students after school to prepare and in the Panel's report manner. The preparation of the report is the student's conscious input process. Only when fully 
understand the content, the students can speak clearly to the other person. Therefore, the students' self and mutual input usually able to do better in intelligibility. Teachers can also make full use of questions. Question itself is easier to focus students' attention, and thus easier to do intelligibility. In addition, teachers should be good at using the repeating strategy. Maintain sensitive to patterns of expression and recurring problems in the subject and reproduce the theory constantly through reviews, lectures, discussions, debates, or make a chart to rebuild the content.

Appropriate output, namely the use of a second or foreign language around the subject content and themes to complete the task of writing or orally, is an important way to strengthen the knowledge and exercise capacity. Different from the mechanical recitation or training, meaningful output is to enable students using naturally of language learning to solve the problem of subject content on the basis of full understanding. Because CBI conjunction with its subject matter, it can make students use the language naturally and get on meaningful output. As long as teachers use appropriately cooperative learning, taskbased teaching, oral presentations, debates, charts, audio, project design and various ways in the class, the students can demonstrate their learning achievement and practice meaningful output in written or spoken way through integrate a variety of information.

\subsection{Design dual assessment objectives and reflect the interdisciplinary requirements}

The curriculum assessment naturally is dual or even threefold adapting to its goals under CBI teaching theory, that teachers should not only examine students' mastery of subject content and the ability to use, but also to examine students' mastery of academic language and ability to use, also examine whether students can smoothly and correctly use second or foreign language to express academic insights, debate, discussion and academic writing. In fact, teachers determine the direction of the assessment at the same time while determining the curriculum goals. Teachers can combine the process assessment with summative assessment to evaluate the students comprehensively.

\section{CONCLUSION}

In summary, the development of bilingual curriculum of course need the overall planning from the national level is concerned, but from the country ideal course to become curriculum students eventually available, one of the most important aspects is teachers, teacher is the ultimate courses enforcer. Qualified bilingual teachers should be both language and professional expertise in content and must be fully prepared compound talent in multiple areas such as a particular academic field, second language acquisition theory, language teaching theory and curriculum design. The bilingual courses teacher's role is at least five: they simultaneously are teachers, curriculum designers and textbook providers, partners, researchers and evaluators. Therefore, bilingual teaching under the guidance of CBI theory is necessarily a very high requirements work, but it also brings encouraging challenges and results.

\section{REFERENCES}

[1] Stoller, F. L. Content-based instruction: Perspectives on curriculum planning. Annual Review of Applied Linguistics, 2004. (24): 261-283.

[2] Met. M. Content-based instruction: Defining terms, making decisions. NFLC Reports. Washington, DC: The National Foreign Language Center, 1999.

[3] Stoller, F.L \& Grabe. W. A six T's approach to contentbased instruction. In Snow, M.A. \& Brinton, D.M. (eds.), The Content-Based Classroom: Perspectives on Integrating Language and Content. NY: Addison Wesley Longman Publishing Company, 78-94.

[4] Cummins, J. The role of primary language development in promoting educational success for language minority students. In Schooling and Language Minority Students: A Theoretical Framework. Los Angeles: California State University, Evaluation, Dissemination, and Assessment Center, 1981, 3-49. 